\title{
Desain Interior Perpustakaan Umum Kota Malang dengan Konsep Friendly dan Penerapan Batik Malang Kuceswara
}

\author{
Marini Septiani ${ }^{1}$, Aria Weny Anggraita ${ }^{2}$ \\ ${ }^{1,2}$ Departemen Interior, Fakultas Arsitektur, Desain, dan Perencanaan, ITS Surabaya \\ Jln. Raya Keputih, Sukolilo - Surabaya 60119 Telp 031.5925223 \\ ${ }^{1}$ septianimarini@gmail.com, 2ariaweny@interior.its.ac.id
}

\begin{abstract}
ABSTRAK
Perkembangan teknologi dan komunikasi berbasis internet memberi kemudahan bagi masyarakat dalam mengakses informasi. Internet menjadi jalan pintas bagi publik untuk mengkonsumsi informasi, perpustakaan yang identik sebagai tempat penyedia informasi harus mampu bersaing dengan perkembangan teknologi. Perpustakaan Umum Kota Malang dengan visi "Terwujudnya pelayanan Perpustakaan terdepan dalam Pembelajaran non-formal serta menjadikan Arsip sebagai keutuhan informasi” memiliki fasilitas yang dapat menjangkau kalangan masyarakat luas seperti anak-anak dan difabel dengan kehadiran ruang baca anak dan layanan pojok braille. Ketika memasuki perpustakaan, penambahan papan informasi dan pentunjuk arah yang jelas dan tepat dapat membantu pengunjung untuk menentukan arah secara mandiri, penambahan fasilitas lift dan guiding block dapat membantu pengunjung difabel untuk menjangkau fasilitas perpustakaan. Pada ruang baca umum, koleksi pustaka dapat ditata kembali dan diberi tanda sesuai dengan jenis buku dan pada ruang baca anak, pengembangan desain pada suasana yang dapat meningkatkan minat baca anak. Visi tersebut diwujudkan melalui pengembangan desain interior perpustakaan lebih lanjut. Metode desain yang diterapkan adalah metode observasi, kueisioner, wawancara dan studi literatur. Data tersebut kemudian diolah dan dianalisa berdasarkan literatur dan kemudian diambil kesimpulan berupa konsep desain. Konsep friendly yang diterapkan pada desain interior perpustakaan bertujuan untuk menciptakan suasana perpustakaan yang bersahabat bagi pengguna perpustakaan untuk mendukung segala aktivitas yang dilakukan pengguna didalam perpustakaan. Batik Malang Kuceswara diterapkan pada desain interior perpustakaan untuk memberikan identitas Kota Malang dalam desain perpustakaan serta mengenalkan budaya Kota Malang kepada masyarakat luas.
\end{abstract}

Kata kunci: batik; friendly; perpustakaan

\section{ABSTRACT}

The development of internet-based technology and communication makes it easy for people to access information. The internet is a shortcut for the public to consume information, library as a place for information providers Should be able to compete with technological developments. Malang Public Library with the vision of "Realizing the foremost library services in non-formal learning and making Archives as information integrity" has facilities that can reach the wider community such as children and disabled people with the presence of children's reading rooms and braille corner services. When entering the library, the addition of information boards and clear and precise directions can help visitors to determine their direction independently, the addition of elevator and guiding block facilities can help visitors with disabilities to reach library facilities. In the public reading room, library collections can be reorganized and marked according to the type of book and in the children's reading room, design development in an atmosphere that can increase children's reading interest. This vision was realized through further development of library interior design. The design method applied is the method of observation, presentation, interview and literature study. The data will processed and analyzed based on literature and conclusions are then taken in the form of design concepts. The friendly concept applied to the interior design of the library aims to create a friendly library atmosphere for library users to support all activities carried out by users in the library. Malang Kuceswara Batik is 
Marini Septiani, Aria Weny Anggraita

Desain Interior Perpustakaan Umum Kota Malang dengan Konsep Friendly dan Penerapan Batik Malang Kuceswara

applied to the interior design of the library to provide the identity of Malang City in library design and to introduce the culture of Malang City to the wider community.

Keyword: batik; friendly; library

\section{PENDAHULUAN}

Pendidikan memiliki peranan yang penting dalam kehidupan manusia dan berpengaruh kepada kemajuan suatu bangsa. Perpustakaan umum sebagai gerbang menuju ilmu pengetahuan bertugas untuk menyediakan informasi yang diperlukan oleh masyarakat sekitarnya agar dapat menopang masyarakat untuk belajar sepanjang hayat (IFLA, 1994).

Berdasarkan studi “The World’s Most Literate Nations” tahun 2016, Indonesia dinyatakan menduduki peringkat ke-60 dari 61 negara mengenai minat membaca (CCSU, 2016). Selain itu perkembangan teknologi dan komunikasi berbasis internet memberi kemudahan bagi masyarakat dalam mengakses informasi. Internet menjadi jalan pintas bagi publik untuk mengonsumsi informasi, perpustakaan yang identik sebagai tempat penyedia informasi harus mampu bersaing dengan perkembangan teknologi.

Perpustakaan Umum Kota Malang dengan visi “Terwujudnya pelayanan Perpustakaan terdepan dalam Pembelajaran Non-Formal serta menjadikan Arsip sebagai keutuhan informasi” memiliki fasilitas yang dapat menjangkau kalangan masyarakat luas seperti anak-anak dan difabel dengan kehadiran ruang baca anak dan layanan pojok braille. Untuk mewujudkan visi tersebut, desain interior perpustakaan perlu dilakukan pengembangan lebih lanjut.

Saat memasuki perpustakaan, penambahan papan informasi dan petunjuk arah yang jelas dan tepat dapat membantu pengunjung untuk menentukan arah secara mandiri di dalam perpustakaan. Penambahan fasilitas lift dan guiding block dapat membantu pengunjung difabel untuk menjangkau area ruang baca umum dan layanan pojok braille yang terletak di lantai 2 . Pada ruang baca umum, area koleksi pustaka dapat ditata kembali dan diberi sign sesuai dengan jenis buku yang terdapat pada rak buku tersebut agar pengunjung dapat dengan mudah mencari buku yang diinginkan. Pada ruang baca anak, pengembangan desain pada suasana yang dapat meningkatkan minat baca anak.

Sebagai destinasi perpustakaan yang diminati masyarakat Kota Malang, perpustakaan kota Malang membangun citra Perpustakaan Umum Kota Malang sebagai tempat tujuan utama masyarakat untuk melakukan pembelajaran non formal dan aktivitas lainnya serta dapat menonjolkan budaya Kota Malang yaitu dengan penerapan motif batik Malang Kuceswara pada desain interior perpustakaan.

\section{METODE PENELITIAN}

\section{A. Metode Pengumpulan Data}

1. Observasi

Observasi dilakukan dengan mengamati aktivitas yang dilakukan oleh pengguna perpustakaan selama berada di perpustakaan.

\section{Wawancara}

Wawancara dilakukan dengan pegawai perpustakaan untuk mengetahui keadaan perpustakaan serta harapan dari pegawai untuk perpustakaan kedepannya.

3. Kuesioner

Kuesioner dilakukan untuk mengetahui kebutuhan pengunjung perpustakaan serta harapan pengunjung untuk perpustakaan kedepannya. 


\section{Studi Literatur}

Studi literatur dilakukan untuk memperkuat dan melengkapi data yang didapatkan sebagai dasar teori untuk mendesain.

\section{B. Metode Analisa Data}

Menggunakan metode kualitatif. Data diperoleh melalui observasi, wawancara, kuisioner dan studi literatur akan diolah dan dianalisa untuk mendapatkan kesimpulan atas pemecahan masalah yang ada sebagai acuan dalam proses desain.

\section{HASIL PENELITIAN DAN PEMBAHASAN}

\section{A. Konsep Desain}

Konsep Friendly merupakan karakter desain yang dapat memberikan suasana yang hangat, mudah dimengerti oleh pengguna, serta mengutamakan kenyamanan pengguna dan dapat mendukung aktivitas pengguna di dalam perpustakaan. Konsep ini diterapkan untuk menciptakan suasana perpustakaan yang bersahabat bagi seluruh pengguna perpustakaan dengan kebutuhan aktivitas mereka yang berbeda-beda untung mendukung segala aktivitas yang pengguna lakukan didalam perpustakaan. serta mengutamakan kenyamanan pengguna yang dapat mendukung aktivitas pengguna di perpustakaan. Konsep penerapan batik Malang Kuceswara dipilih untuk memberikan ciri khas pada desain interior perpustakaan dengan menerapkan motif-motif dari batik Malang Kuceswara.

\section{B. Konsep Makro}

1. Konsep Friendly

Konsep friendly yang diterapakan pada desain interior perpustakaan terdiri dari 3 aspek, yaitu: suasana hangat, mudah dimengerti, dan kenyamanan (Gambar 1).

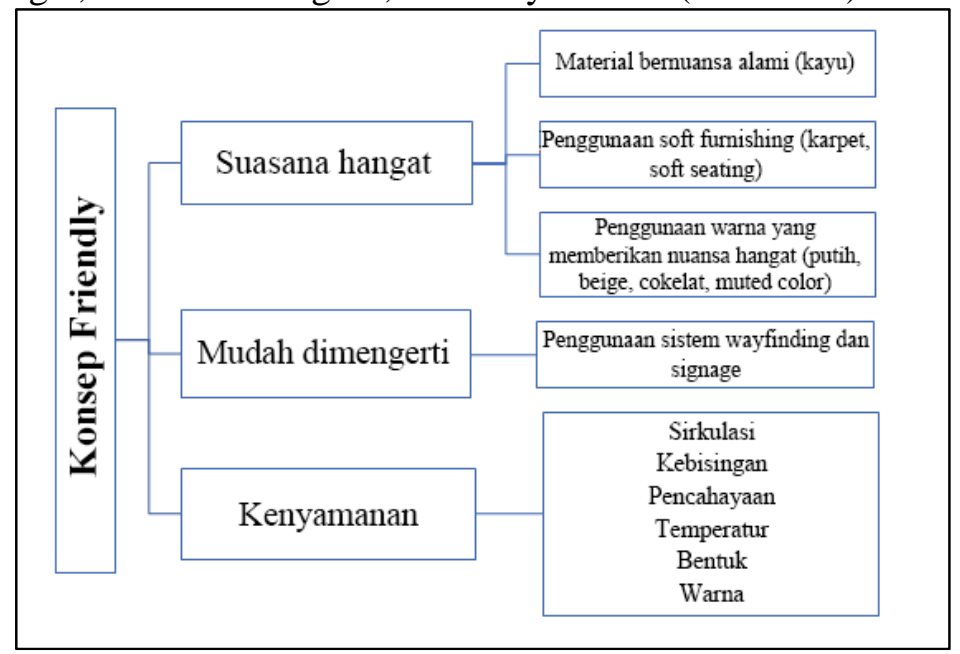

Gambar 1. Aspek dalam Konsep Friendly Sumber: Dokumentasi Penulis (2018)

\section{Konsep Batik Malang Kuceswara}

Motif batik Malang Kuceswara (Gambar 2) akan diterapkan pada desain interior perpustakaan. Selain menggunakan motif batik secara keseluruhan, 3 dari 7 motif batik Malang Kuceswara yang diterapkan dalam desain interior, antara lain: motif tugu pahlawan, motif rambut singa, dan isen-isen belah ketupat. Ketiga motif tersebut akan ditransformasi dan 
dijadikan bentukan yang lebih sederhana untuk kemudian diterapkan dalam interior perpustakaan (Gambar 3).

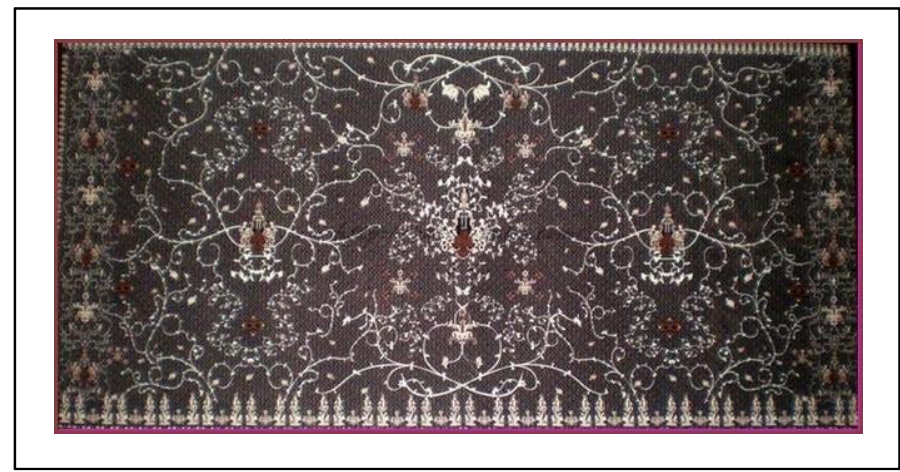

Gambar 2. Motif Batik Malang Kuceswara

Sumber: www.google.com (2018)

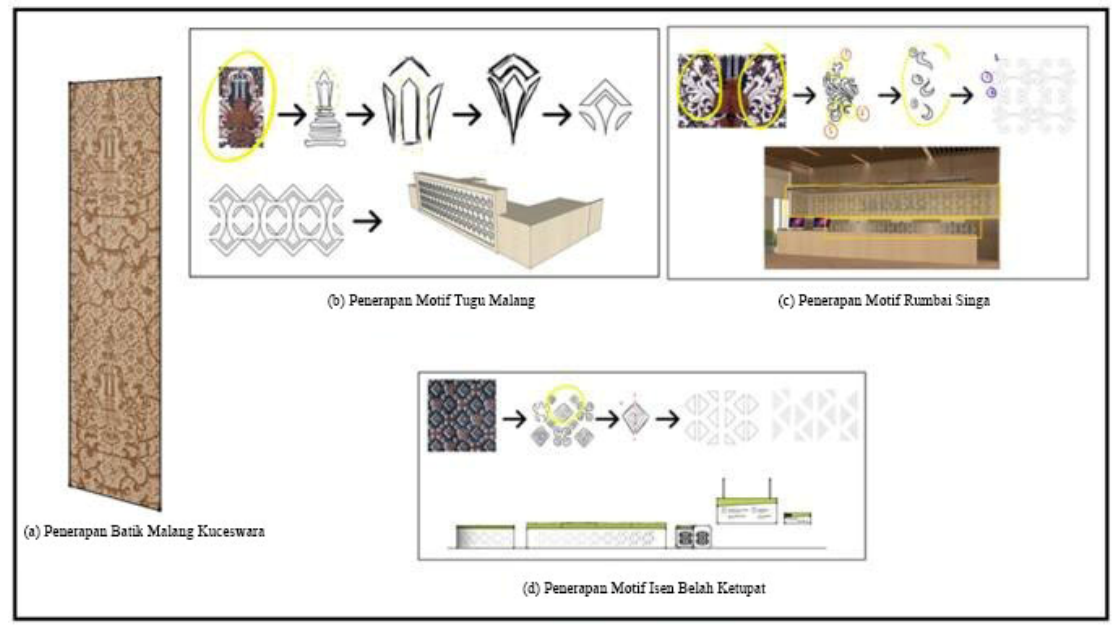

Gambar 3. Penerapan Batik Malang Kuceswara Sumber: Dokumentasi Penulis (2018)

\section{Konsep Mikro}

\section{Konsep Warna}

Warna yang diterapkan pada desain interior perpustakaan adalah warna yang dapat memberikan nuansa hangat serta nyaman dalam rungan seperti warna coklat (Marsya dan Anggraita, 2016). Selain warna coklat, warna yang memberikan nuansa hangat dalam ruangan antara lain putih, beige, dan muted color seperti abu-abu (Indrani, 2004). Warna hijau digunakan sebagi warna aksentuasi untuk memberikan kesan seimbang dan menyegarkan (Groenholm, 2010).

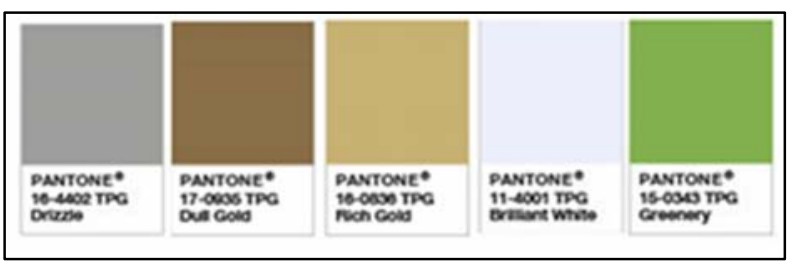

Gambar 4. Konsep Warna Sumber: www.google.com (2018) 


\section{Konsep Dinding}

Material yang akan digunakan pada dinding, antara lain: panel-panel laminasi motif kayu, panel-panel laminasi kustom motif batik Malang Kuceswara serta dinding yang dilapisi dengan cat putih.

\section{Konsep Lantai}

Material lantai yang digunakan memiliki karakteristik penyerap suara yang baik, material yang digunakan antara lain vinyl motif kayu cerah, vinyl abu-abu cerah, dan karpet berwana hijau. Material penutup lantai yang berbeda digunakan untuk menciptakan zonasi antar ruang. Pada lantai disediakan pula guiding block untuk membantu aktivitas pengunjung difabel netra di dalam perpustakaan.

\section{Konsep Plafond}

Plafond pada perpustakaan menggunakan material gypsum dengan finishing cat putih serta baffle ceiling dengan motif kayu untuk memberikan kesan hangat ke dalam ruangan. Permainan tinggi-rendah pada plafond akan diterapkan untuk menghidari kesan monoton dalam ruangan.

\section{Konsep Furnitur}

Furnitur yang digunakan di dalam perpustakaan merupakan furnitur ergonomis yang disesuaikan dengan aktivitas pengguna perpustakaan untuk mendukung aktivitas mereka dan memberikan kenyamanan.

\section{Hasil Akhir}

1. Ruang Terpilih 1 - Lobby

Lobby perpustakaan merupakan area dimana pengunjung dapat menerima layanan perpustakaan berupa: layanan informasi, layanan keanggotaan dan layanan peminjaman kunci loker. Meja layanan informasi diletakkan tepat didepan pintu masuk perpustakaan untuk mempermudah pengunjung menerima layanan yang disediakan. Untuk menggunakan layanan yang dibutuhkan, pengunjung dapat melihat signage gantung pada area meja layanan informasi. Nuansa hangat dalam area lobby tercipta dengan penggunaan material bernuansa kayu berupa: panel dinding laminasi motif kayu, cladding kolom laminasi motif kayu, baffle ceiling bermotif kayu serta material pelapis lantai yaitu vinyl motif kayu. Motif batik Malang Kuceswara diterapkan melalui penggunaan panel dinding kustom laminasi motif batik Malang Kuceswara, pengembangan motif tugu malang pada meja layanan informasi serta signage gantung dengan motif batik Malang Kuceswara.

Pada lantai lobby perpustakaan terdapat guiding block yang dapat membantu pergerakan pengunjung difabel netra di dalam perpustakaan.

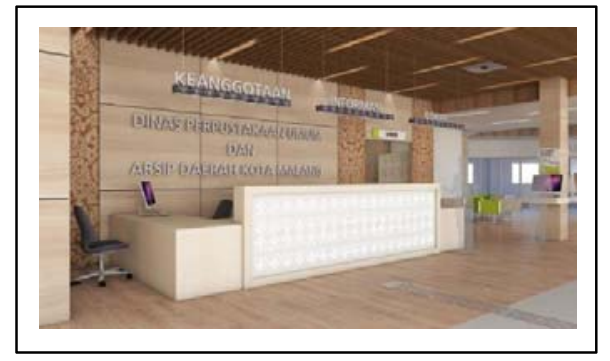

Gambar 5. Desain Lobby Perpustakaan Sumber: Dokumentasi Penulis (2018) 


\section{Ruang Terpilih 2 - Ruang Baca Umum}

Ruang baca umum merupakan ruangan dimana pengunjung dapat membaca, meminjam dan mengembalikan buku. Pada ruangan ini tersedia ruang referensi dan layanan pojok braille. Nuansa hangat dalam ruangan ini tercipta dengan penggunaan furnitur-furnitur bermotif kayu, baffle ceiling motif kayu dan cladding kolom motif kayu. Penggunaan material penutup lantai yang berbeda pada ruangan ini bertujuan untuk memberikan zonasi pada ruangan, dimana area yang mengunakan karpet hijau ditujukan untuk area baca, area yang menggunakan vinyl kayu ditujukan untuk area layanan dan koleksi pustaka, serta area yang menggunakan vinyl abu-abu merupakan area sirkulasi utama.

Gambar 6 merupakan area koleksi pustaka, rak buku pada area koleksi pustaka ditata sesuai tata urut Dewey, dimulai dari nomor panggilan koleksi 000 (karya umum) hingga nomor panggilan koleksi 900 (biografi ilmu bumi, sejarah). Di setiap rak buku diberi signage nomor panggilan koleksi buku untuk memudahkan pengunjung dalam mencari buku. Katalog komputer disediakan di area koleksi pustaka agar pengunjung dapat mecari judul buku yang diinginkan pada katalog tersebut. Ruang Terpilih 3 - Ruang Baca Anak

Gambar 7 dan 8 merupakan area baca santai. Area baca pada Gambar 7 dengan dudukan berupa stool dan bench ditujukan bagi pengunjung yang ingin langsung membaca buku yang telah diambilnya, area ini terletak diantara rak koleksi buku baru dan area pustaka. Stool dan bench yang digunakan pada area ini merupakan furnitur kustom yang terinspirasi dari motif isen belah ketup batik Malang Kuceswara.

Gambar 8 merupakan area baca santai yang ditujukan bagi pengunjung yang ingin membaca atau melakukan aktivitas dengan nyaman dengan tersedianya soft seating dan highback chair sembari melihat pemandangan pada Jalan Ijen.

Gambar 9 merupakan area baca dimana pengunjung dapat membaca menggunakan meja dan kursi yang tersedia. Pada area membaca ini, setiap meja dilengkapi dengan soket listrik untuk memudahkan pengunjung yang menggunakan laptop. Penggunaan panel akustik warna hijau pada area ini bertujuan untuk memberikan efek menyegarkan pada ruangan sehingga pengunjung dapat melakukan aktivitas dengan baik.

Gambar 10 merupakan area layanan sirkulasi dimana pengunjung dapat meminta informasi, meminjam dan mengembalikan buku. Backdrop pada area layanan ini merupakan kombinasi antara panel dinding laminasi motif kayu dan panel dinding laminasi transformasi motif rumbai singa batik Malang Kuceswara.

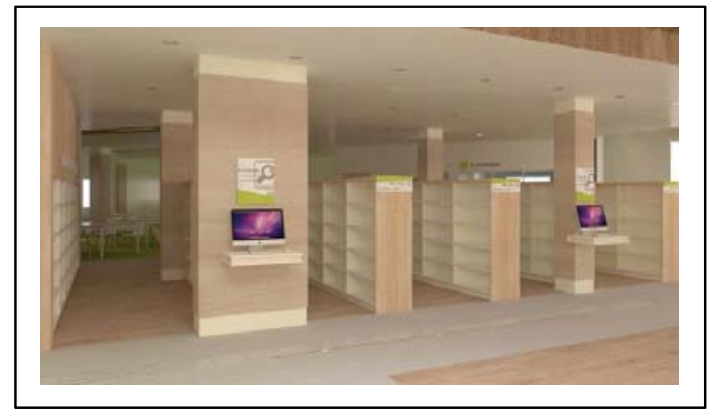

Gambar 6. Area Koleksi Pustaka Sumber: Dokumentasi Penulis (2018)

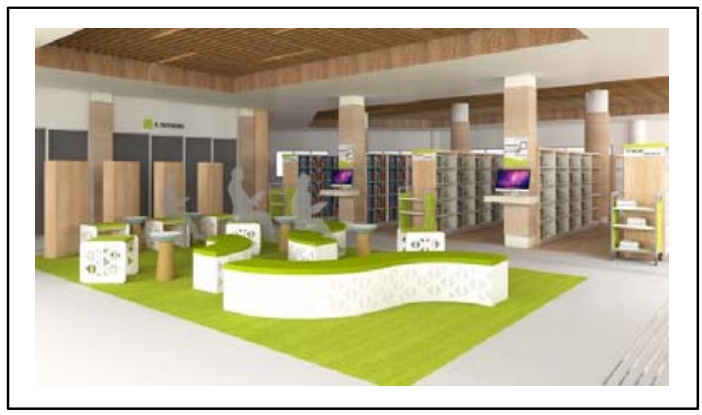

Gambar 7. Area Baca Santai 1 Sumber: Dokumentasi Penulis (2018) 


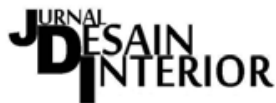

Vol. 4, No. 1, Juni 2019, pISSN 2527-2853, eISSN 2549-2985

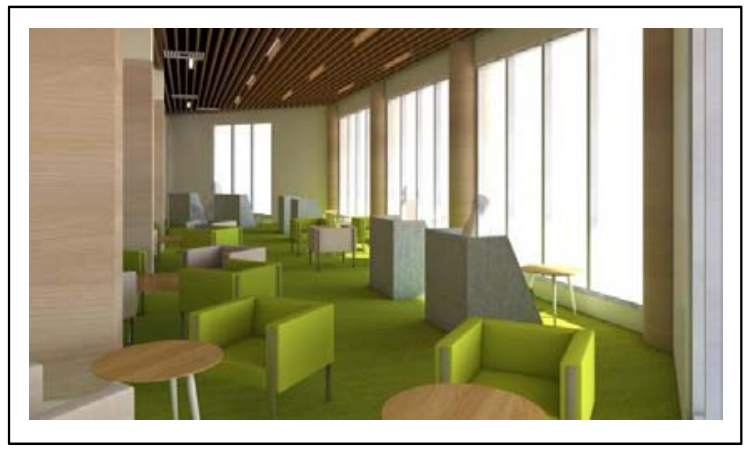

Gambar 8. Area Baca Santai 2 Sumber: Dokumentasi Penulis (2018)

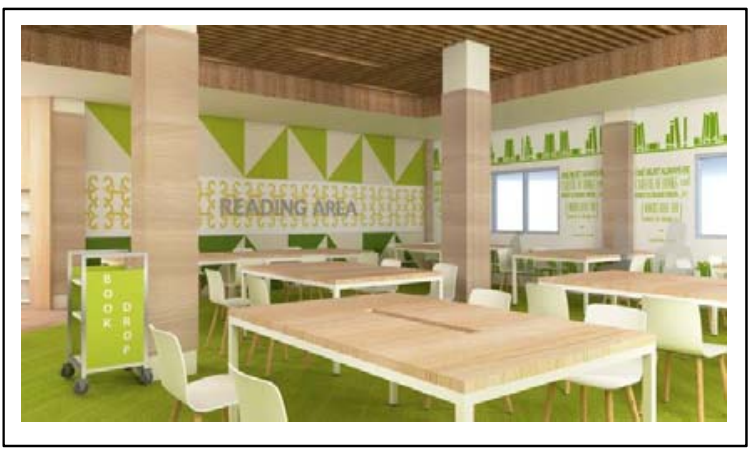

Gambar 9. Area Baca Sumber: Dokumentasi Penulis (2018)

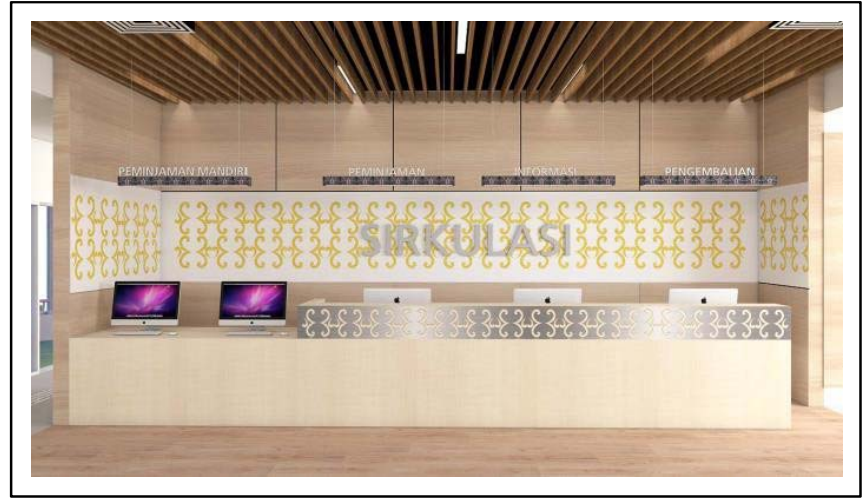

Gambar 10. Layanan Sirkulasi

Sumber: Dokumentasi Penulis (2018)

3. Ruang Terpilih 3 - Ruang Baca Anak

Ruang baca anak dirancang agar pengguna anak-anak bersama dengan pendampingnya dapat beraktivitas dengan nyaman di dalam ruangan. Interior ruang baca anak didesain untuk membentuk suasana seperti alam.

Gambar 11 dan 12 merupakan area baca dan koleksi buku. Pada Gambar 11 tersedia area baca dengan meja dan kursi dan rak buku berbentuk semi-circular yang juga berfungsi sebagai pembatas dengan area baca lesehan.

Gambar 12 merupakan area baca lesehan dengan lantai berlapis karpet agar pengguna dapat membaca dengan nyaman. Area baca ini dapat diakses menggunakan tangga yang berada di kedua sisi ruangan. Rak buku pada area ini didesain menyerupai pepohonan untuk memberikan kesan alam. Koleksi buku dapat dicari menggunakan signage berbentuk rumah berwarna hijau yang terdapat di rak buku.

Gambar 13 merupakan area mendongeng dimana anak-anak dapat mendengarkan cerita, menonton animasi ataupun membaca. Material karpet digunakan sebagai penutup lantai untuk memberikan kenyamanan kepada anak-anak, selain itu disediakan dudukan berupa cushioncushion untuk mereka gunakan. Pada dinding area mendongeng diberi panel dinding berbentuk segitiga berwarna hijau yang disusun untuk memberikan kesan berada di pegunungan 


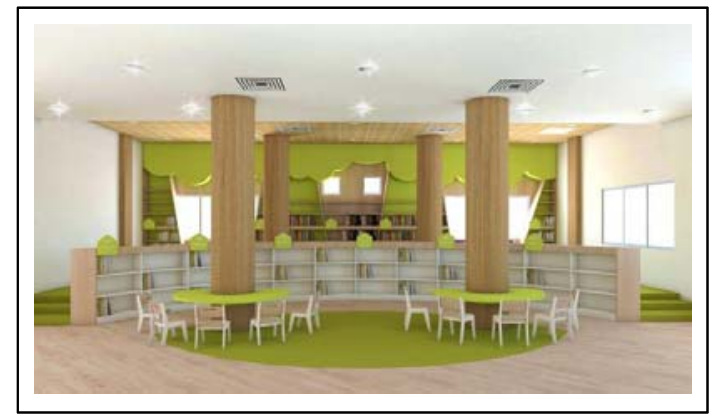

Gambar 11. Area Koleksi Buku dan Area Membaca Sumber: Dokumentasi Penulis (2018)

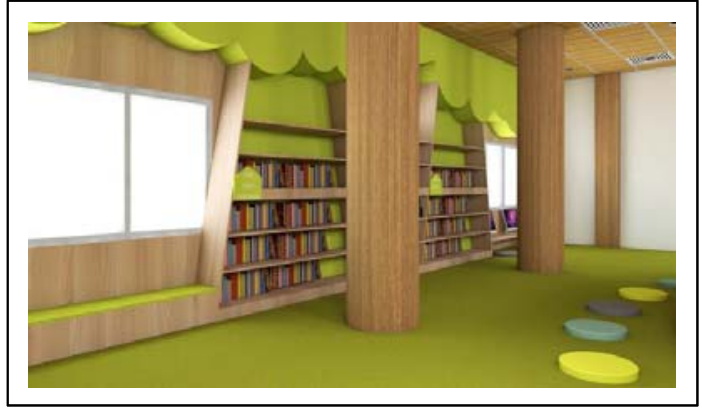

Gambar 12. Area Koleksi Buku dan Area Membaca Lesehan Sumber: Dokumentasi Penulis (2018)

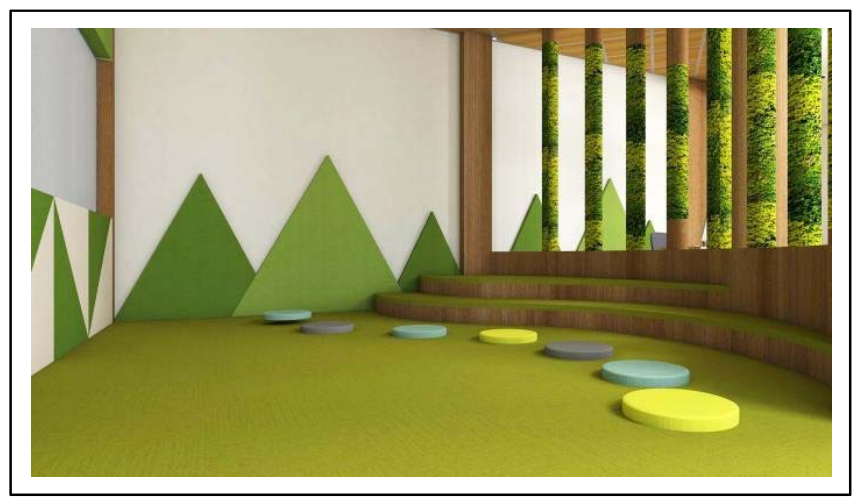

Gambar 13. Area Mendongeng

Sumber: Dokumentasi Penulis (2018)

\section{KESIMPULAN}

Kesimpulan yang didapat dari "Desain Interior Perpustakaan Umum Kota Malang dengan Konsep Friendly dan Penerapan Batik Malang Kuceswara”, yaitu:

1) Perpustakaan Umum Kota Malang merupakan destinasi perpustakaan yang cukup diminati masyarakat Kota Malang terutama dari kalangan pelajar. Perpustakaan juga memiliki fasilitas yang menjangkau kalangan masyarakat luas dengan tersedianya fasilitas ruang baca anak dan layanan pojok braille.

2) Konsep friendly pada perpustakaan bertujuan untuk menciptakan suasana perpustakaan yang bersahabat bagi seluruh pengguna perpustakaan untuk mendung aktivitas yang mereka lakukan. Konsep ini ditampilkan melalui karakter desain yang bernuansa hangat dengan pengaplikasian material bernuansa natural (bermotif kayu) serta menggunakan warna-warna bernuansa hangat (putih, beige, coklat, abu-abu), mudah dimengerti dengan pengaplikasian signage yang tepat (sign penunjuk arah, sign informasi, sign koleksi buku) serta mengutamakan kenyaman pengguna dengan memerhatikan aspek sirkulasi, kebisingan, pencahayaan, temperatur, bentuk, warna dan dapat mendukung aktivitas di dalamnya.

3) Penerapan batik Malang Kuceswara pada interior ruangan dipilih untuk memberikan ciri khas pada desain interior Perpustakaan Umum Kota Malang serta memperkenalkan batik Malang Kuceswara kepada masyarakat. 


\section{DAFTAR PUSTAKA}

CCSU. (2016). World's Most Literate Nations Ranked. (Online). (https://webcapp.ccsu.edu/?news=1767\&data, diakses 3 September 2017).

Groenholm, Micco. (2010). Olor Psychology (the "Colour Affects” system). (Online). (http://micco.se/wp-content/uploads/2010/05/Micco- Groenholm-on-Color-AffectsSystem.pdf, diakses 3 September 2017).

IFLA. (1994). IFLA/UNESCO Public Library Manifesto $1994 . \quad$ (Online). (https://www.ifla.org/publications/iflaunesco-public-library-manifesto-1994, diakses 3 September 2017).

Indrani, Hedy C. (2004). Perancangan Suasana Hangat pada Interior Hunian Modern. Jurnal Dimensi Interior. Vol. 2 No. 2 Hlm. 147-165.

Marsya, Intan Hannah dan Anggraita, Aria Weny. (2016). Studi Pengaruh Warna pada Interior Terhadap Psikologis Penggunanya, Studi Kasus pada Unit Transfusi Darah Kota X. Jurnal Desain Interior. Vol. 1 No. 1 Hlm. 41-50 Edisi April 2016. 
Marini Septiani, Aria Weny Anggraita

Desain Interior Perpustakaan Umum Kota Malang dengan Konsep Friendly dan Penerapan Batik Malang Kuceswara 